\title{
The role of outliers and oil price shocks on volatility of metal prices
}

\author{
Niaz Bashiri Behmiri ${ }^{\mathrm{a}, *}$, Matteo Manera ${ }^{\mathrm{b}}$ \\ a Fondazione Eni Enrico Mattei FEEM, Italy \\ ${ }^{\mathrm{b}}$ University of Milan-Bicocca and FEEM, Italy
}

\section{A R T I C L E I N F O}

\section{Article history:}

Received 13 July 2015

Received in revised form 9 September 2015

Accepted 9 September 2015

Available online 30 September 2015

\section{Keywords:}

Metals

Commodities

Volatility

Oil price

Outliers

\begin{abstract}
A B S T R A C T
This study investigates the price volatility of metals, using GARCH and GJR models. First, we examine the persistence of volatility and the leverage effect across metal markets taking into account the presence of outliers. Second, we estimate the effects of oil price shocks on the price volatility of metals, allowing for asymmetric responses. We use daily spot prices for aluminum, copper, lead, nickel, tin, zinc, gold, silver, palladium and platinum. We find that returns have a high degree of volatility persistence before and after correcting for outliers, outliers bias the estimation of GARCH and GJR models, and removing outliers improves volatility modelling. However, Student-t-based specifications outperform outliers correction in capturing volatility. Moreover, we document inverse leverage effects for seven metals, leverage effect for copper and no leverage effects for nickel and palladium. Finally, price volatility of metals reacts differently and asymmetrically to oil price shocks.
\end{abstract}

(c) 2015 Elsevier Ltd. All rights reserved.

\section{Introduction}

Investigating volatility in metal markets is an attractive subject for financial traders and manufacturers. Metal prices are generally subject to a lot of speculative trades (Moore and Cullen, 1995), especially that in recent years increasing speculative activities in emerging economies lead to more uncertainty and volatility in these markets (Gil-Alana and Tripathy, 2014). Volatility can affect the decision of investors for portfolio allocation and Value at Risk management, as well as the industrial production of manufacturers and therefore the economic growth pattern of nations. As a result, the correct modeling of volatility in metal markets is a crucial issue, which on one side increases the ability to generate more accurate out-of-sample forecasting of prices for policymakers, and on another side facilitates the Value at Risk management strategies for financial traders.

The topic of investigating volatility in non-energy commodity markets, metals and agricultures, are less considered in the literature comparing to stock and energy markets. In this context, Mckenzie et al. (2001) investigate the volatility of precious metal prices using the univariate power ARCH model and do not find an asymmetric effect in metal markets, Hammoudeh and Yuan (2008) apply the univariate GARCH-type models to examine the volatility of gold, silver and copper prices while controlling the shocks by including oil price and the US interest rate. They find an inverse

\footnotetext{
* Correspondence to: Corso Magenta, 63, 20123 Milano, Italy.

E-mail addresses: niaz.bashiri@feem.it, Bashiri.niaz@gmail.com (N.B. Behmiri).
}

leverage effect in the gold and silver markets and a leverage effect in the copper market, Hammoudeh et al. (2011) examine the volatility of precious metal prices using the GARCH-type models and develop the corresponding risk management effect. Morales and O'Callaghan (2011) investigate the volatility of precious metal prices before and after the global and the Asian financial crises, applying the GARCH and the EGARCH models. They show strong evidences for the volatility persistence in metal markets during the global financial crisis; however, this effect was very weak during the Asian financial crisis, Chkili et al. (2014) assess the asymmetry and long memory effects in modeling the volatility of crude oil, natural gas, gold and silver prices, employing the GARCH-type models. They find a leverage effect in oil and natural gas markets and find an inverse leverage effect in gold and silver markets; furthermore, their results reveal that there is lower persistence for the gold and silver markets compared to those of oil and natural gas, Gil-Alana and Tripathy (2014) analyze the volatility persistence and the leverage effect for non-precious metal markets in India, using the GARCH-type models. They find a high degree of volatility persistence for all metals, the asymmetric effect is found for seven metals according to the TGARCH model and for ten metals according to the EGARCH model. Finally Todorova et al. (2014) examine volatility spillovers between non precious metals, applying the multivariate Heterogeneous Autoregressive (HAR) model. They reveal that the volatility of other industrial metals contain useful information for the future price volatility; however, the own dynamics of each metal are mostly sufficient to explain the future daily and weekly volatility. 
Another critical issue is the effect of oil price shocks on commodity markets, Ji and Fan (2012) state that in recent years the substitution of fossil fuels by biofuels as well as hedge strategies against inflation caused by higher oil prices have increased. These reasons surge the linkages between crude oil and non-energy markets, including agricultures and metals. In this context, some studies focus on volatility spillovers between metals and energy markets, using the bivariate or multivariate GARCH-type models (see e.g., Choi and Hammoudeh, 2010; Ji and Fan, 2012; Mensi et al., 2013; Ewing and Malik, 2013; Charlot and Marimoutou, 2014); some apply volatility indices to examine uncertainty transmission between oil, non-energy commodities and stocks using the cointegration and the Granger causality approaches (see e.g., Liu et al., 2013); a number of studies examine the relation between oil and metal prices applying the cointegration and the Granger causality procedures (see e.g., Soytas et al., 2009; Zhang and Wei, 2010; Sari et al., 2010; Jain and Ghosh, 2013; Mensi et al., 2013); and finally a few studies apply the univariate GARCH-type models to examine volatility of metals while including oil prices as the control variable to the mean and variance equations (see e.g., Hammoudeh and Yuan, 2008).

However, none of the above mentioned studies take into account the role of exogenous events on volatility of metal prices. As Charles and Darné (2014a) state, financial markets are affected by specific incidents that can impact on modeling financial time series. These events, such as wars, natural disasters, political conflicts, etc., that are mostly unpredictable, are the so-called outliers. Outliers can affect identification and estimation of the GARCH-type models (Carnero et al., 2007, 2012); they can wrongly suggest conditional heteroscedasticity or hide true heteroscedasticity (see e.g., Balke and Fomby, 1994; Dijk et al., 1999; Franses and Ghijsels, 1999; Aggarwal et al., 1999; Carnero et al., 2007); they can bias the GARCH parameters estimation (see e.g., Sakata and White, 1998; Mendes, 2000; Charles, 2008); and they can affect out-of-sample forecasts (see e.g., Franses and Ghijsels, 1999; Carnero et al., 2007; Charles, 2008).

To solve the problem of outliers, Ané et al. (2008) examine the price volatility of Asia-Pacific stock market after detecting outliers in a GARCH model, using their own proposed approach. Moreover, Charles and Darné (2014a,b) estimate the price volatility of crude oil and Dow Jones industrial average index, respectively, after detecting and correcting outliers in the GARCH-type models, applying the Laurent et al. (2013) outlier detection method. However, to the best of our knowledge, there is no study in the literature that takes into account the presence of outliers in volatility of nonenergy commodity markets.

The current study sought to achieve two main objectives. The first one is to examine the persistence of volatility and the leverage effects in four precious and six industrial metals, employing the GARCH and the GJR models, considering outliers. To achieve this goal we use two alternative approaches to capture outliers in the series, one is employing the widely used approach of Student- $t$ distribution suggested by Bollerslev (1987), and the second one is identifying and correcting outliers in the GARCH-type models applying the Doornik and Ooms (2005) outlier detection procedure. The second objective is to examine the effect of oil price shocks on the price volatility of metals, taking into account the presence of outliers; moreover, we allow for the asymmetric responses of price volatility to the changes of oil returns. These investigations provide two original contributions to the existing commodity markets literature: investigating the effect of extreme events on modeling of volatility, and estimating the asymmetric responses of volatility to the negative and positive oil price shocks in metal markets, which have not been investigated in the relevant studies.

The rest of this paper is organized as follows. Data description and methodology are reported in Section 2. Section 3 describes the results, while Section 4 concludes.

\section{Data description and methodology}

\subsection{Data description}

We use daily spot closing price series for six industrial metals, including aluminum, copper, lead, nickel, tin, zinc; and four precious metals, comprising gold, silver, palladium and platinum, traded on the LME (London Metal Exchange). Moreover, we apply daily spot closing price series for Brent crude oil, traded on ICE (Intercontinental Exchange). The time span is from July 1993 to January 2014,which has the advantage of covering the 1997 Asian financial crisis, the 2008 and the 2012 oil price shocks, the 2008 global financial crisis and the 2008 stock market crash. The prices are converted to log returns by means of $R_{t}=\log \left(\frac{P_{t}}{P_{t-1}}\right)$, where $R_{t}$ is the corresponding returns and $P_{t}$ is the corresponding price series.

All return series have the Kurtotis statistics greater than three representing the existence of fat tails, they have the negative skewness statistics suggesting the presence of left fat tails, expect for nickel that shows a small right tail. Moreover, the Jarque-Bera statistics indicate non-linearity for all return series at the $1 \%$ level of significance. The residual diagnostics tests suggest that there is an ARCH effect for all returns at the $1 \%$ level of significance, thus returns of metals suffer from heteroskedasticity, the results are shown for one lag. Furthermore, according to Ljung-Box Q-test for residuals there are enough evidences for presence of serial correlation up to 20 lags. In order to check for stationarity properties of the series we apply the Augmented Dickey and Fuller (1979) (ADF) and the Phillips and Perron (1988) (P-P) unit root tests. According to the both tests the level of metal prices contain unit roots and their returns are stationary; hence, they are suitable for subsequent tests in this study. The description of returns are shown in Table 1.

\subsection{Persistence of volatility and leverage effect}

In order to estimate the volatility persistence in metal markets we apply the GARCH model developed by Bollerslev (1987):

$y_{t}=\beta^{\prime} x_{t}+\varepsilon_{t} ; \varepsilon_{t}=z_{t} \sqrt{h_{t}} ; \varepsilon_{t} \sim N\left(0, \sqrt{h_{t}}\right) ; z_{t} \sim i . i . d, N(0,1)$

$h_{t}=\alpha_{0}+\sum_{i=1}^{p} \alpha_{i} \varepsilon_{t-i}^{2}+\sum_{i=1}^{q} \beta_{i} h_{t-j}$

where $\varepsilon_{t-i}^{2}$ denotes the ARCH term and $h_{t-i}$ denotes the GARCH term. The parameters should satisfy $\alpha_{0}>0, \quad \sum_{i=1}^{p} \alpha_{i} \geq 0$ and $\sum_{i=1}^{q} \beta_{i} \geq 0$, to guarantee the non-negativity of the conditional variance. The necessary and sufficient condition for the second order stationarity of the $\operatorname{GARCH}(\mathrm{p}, \mathrm{q})$ model is $\sum_{i=1}^{p} \alpha_{i}+\sum_{i=1}^{q} \beta_{i}<1$. This condition is sufficient for the $\mathrm{QMLE}^{1}$ to be consistent and asymptotically normal. However, later Nelson (1990) obtains the necessary and sufficient conditions for strict stationarity, $E\left(\log \left(\alpha \eta_{t}^{2}+\beta\right)<0\right.$ as the $\log$-moment condition, which allows for $\alpha+\beta \geq 1$ if $E \varepsilon_{t}^{2}=\infty$.

In the next step, we apply the Glosten-Jagannathan-Runkle GARCH (GJR-GARCH) model proposed by Glosten et al. (1993) to analyze the asymmetry and the leverage effects in the GARCH process:

\footnotetext{
${ }^{1}$ Quasi Maximum Likelihood.
} 
Table 1

Description of returns.

\begin{tabular}{|c|c|c|c|c|c|c|c|c|c|}
\hline & \multicolumn{3}{|c|}{ Data description } & \multicolumn{2}{|l|}{ Diagnostics } & \multicolumn{4}{|c|}{ Unit root tests } \\
\hline & Skewness & Kurtosis & $J-R$ & $\begin{array}{l}\text { ARCH } \\
F \text {-stat }\end{array}$ & $\begin{array}{l}\text { Serial correlation } \\
\text { Qstat(lag20) }\end{array}$ & $\begin{array}{l}\text { ADF } \\
\text { Levels } \\
t \text {-stat }\end{array}$ & P-P & $\begin{array}{l}\text { ADF } \\
\text { Returns } \\
t \text {-stat }\end{array}$ & $\mathrm{P}-\mathrm{P}$ \\
\hline Aluminum & -0.275 & 5.56 & 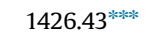 & $61.65^{* * * * *}$ & $32.62^{* * * k}$ & -2.34 & -2.26 & $-72.22^{\text {***** }}$ & 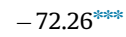 \\
\hline Copper & -0.159 & 7.68 & 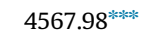 & $217.61^{* * * *}$ & 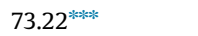 & -1.68 & -1.60 & $-73.35^{* * * *}$ & $-73.39^{* * * * *}$ \\
\hline Lead & -0.129 & 6.49 & $2535.51^{\text {***** }}$ & $222.02^{* * * * k}$ & $56.71^{* * * *}$ & -2.08 & -1.92 & 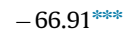 & $-66.86^{* * * k *}$ \\
\hline Nickel & 0.003 & 7.80 & $4779.09^{\text {***k* }}$ & $206.39^{* * * * k}$ & 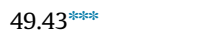 & -1.88 & -1.86 & 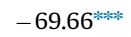 & $-69.66^{\text {*klek }}$ \\
\hline Tin & -0.108 & 10.45 & 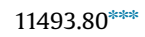 & 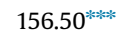 & $47.74^{* * * *}$ & -1.93 & -1.90 & $-68.69^{* * * * *}$ & 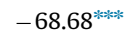 \\
\hline Zinc & -0.247 & 6.98 & 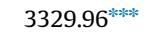 & $144.09^{* * * * \cdots * k ~}$ & $43.48^{* * * *}$ & -1.99 & -1.91 & 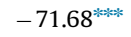 & 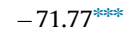 \\
\hline Gold & -0.209 & 9.56 & 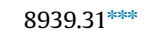 & 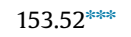 & $39.61^{* * * *}$ & -1.91 & -1.90 & 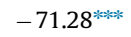 & $-71.28^{* * * * * k}$ \\
\hline Palladium & -0.158 & 8.86 & 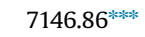 & $140.26^{* * * * *}$ & $42.33^{* * * *}$ & -1.83 & -1.80 & $-67.44^{\text {***** }}$ & $-67.40^{* * * * *}$ \\
\hline Platinum & -0.707 & 13.07 & 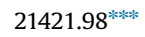 & $182.11^{\text {**k*k }}$ & 25.18 & -2.66 & -2.59 & $-70.97^{\text {*冰水 }}$ & $-71.01^{\text {米冰水 }}$ \\
\hline Silver & -0.454 & 12.23 & $17814.79^{* * * * *}$ & $438.00^{* * * * *}$ & $75.49^{* * * * *}$ & -2.23 & -2.30 & $-76.53^{\text {**** }}$ & $-76.53^{\text {***** }}$ \\
\hline
\end{tabular}

Notes:

$\mathrm{J}-\mathrm{R}$ denotes the Jarque-Bera test.

ADF denotes the Augmented Dickey Fuller unit root test.

$\mathrm{P}-\mathrm{P}$ denotes the Phillips Perron unit root test.

* indicates statistical significance at $10 \%$ level.

** indicates statistical significance at $5 \%$ level.

*** indicates statistical significance at $1 \%$ level.

$$
\begin{aligned}
h_{t} & =\alpha_{0}+\sum_{i=1}^{p} \alpha_{i} \varepsilon_{t-i}^{2}+\sum_{i=1}^{q} \beta_{i} h_{t-j}+\sum_{k=1}^{r} \gamma_{k} I_{t-k} \varepsilon_{t-k}^{2} \text { where } I_{t-k} \\
& = \begin{cases}1 & \text { if } \varepsilon_{t-k}<0 \\
0 & \text { if } \varepsilon_{t-k} \geq 0\end{cases}
\end{aligned}
$$

In this model, the parameters should satisfy $\alpha_{0}>0$, $\sum_{i=1}^{p} \alpha_{i}+\sum_{k=1}^{r} \gamma_{k} / 2 \geq 0$ and $\sum_{i=1}^{q} \beta_{i} \geq 0$, to guarantee the non-negativity of the conditional variance. Moreover, the second order stationarity condition should be satisfied as $\sum_{i=1}^{p} \alpha_{i}+\sum_{i=1}^{k} \gamma_{k} / 2+\sum_{i=1}^{q} \beta_{i}<1$. Ling and McAleer (2002a,b) develop the second order stationarity of the GJR(1,1) model as a sufficient condition for consistency and asymptotic normality of the QMLE. Nevertheless, later McAleer et al. (2002) obtain the necessary and sufficient condition for strict stationarity by extending the log-moment condition for the $\operatorname{GJR}(1,1)$ model, as $E\left(\log \left(\left(\alpha+\gamma I\left(\eta_{t}\right)\right) \eta_{t}^{2}+\beta\right)\right)<0$, this allows for $\alpha+\frac{\gamma}{2}+\beta \geq 1$ if $E \varepsilon_{t}^{2}=\infty$.

\subsection{Outlier detection}

The existing methodologies to detect outliers are divided into two categories: methods to detect outliers in linear models (see e.g., Tsay, 1986; Chang et al., 1988; Chen and Liu, 1993) and methods to detect outliers in nonlinear models (see e.g., Sakata and White, 1998; Hotta and Tsay 1998; Franses and Ghijsels, 1999; Charles and Darné, 2005; Zhang and King, 2005; Doornik and Ooms, 2005; Laurent et al., 2013). In this study we apply the Doornik and Ooms (2005) procedure to detect the additive outliers in the GARCH-type models. Their proposed approach is inspired by Chen and Liu (1993) who develop an outlier detection procedure in a standard time series model. In the process of detecting additive outliers, it is important to distinguish between level outliers and volatility outliers. The additive level outliers affect the level of the series and the additive volatility outliers affect the future conditional variances, meaning that outliers in the series affect underlying conditional variances (see Sakata and White, 1998; Hotta and Tsay, 1998). In this context, Doornik and Ooms (2005) introduce a nesting model for generalized additive outliers (gao), which nests both the additive level and the additive volatility outliers in the GARCH process. Based on this approach the

following five steps procedure is applied:

The first step is to estimate a GARCH model to obtain the log likelihood $\hat{l}$, residuals $\varepsilon_{t}$ and volatility $h_{t}$, and the largest standardized residuals in absolute value, $\max _{t}\left|\frac{\varepsilon_{t}}{h_{t}}\right|$. The second step is to re-estimate a GARCH generalized additive outlier model with adding a single-observation dummy variable, $d_{t}$, in the mean equation as well as adding a single-observation lagged dummy variable,$d_{t-1}$, in the variance equation. The first dummy, $d_{t}$, corresponds to the date of the largest standardized residuals, $\left(\max _{t}\left|\frac{\varepsilon t}{h_{t}}\right|\right)$, obtained from step one, in which $d_{t}$ equals one where $t=\max _{t}\left|\varepsilon_{t} / h_{t}\right|$ and zero otherwise, and the second dummy, $d_{t-1}$, relates to the date of the largest standardized residuals $\left(\max _{t}\left|\frac{\varepsilon_{t}}{h_{t}}\right|\right)$ with one period lag, in which $d_{t-1}$ equals one where $t=\left(\max _{t}\left|\varepsilon_{t} / h_{t}\right|\right)+1$ and zero otherwise. The GARCH generalized additive outlier model can be written as:

$y_{t}=\beta^{\prime} x_{t}+\gamma d_{t}+\varepsilon_{t}$

$h_{t}=\alpha_{0}+\sum_{i=1}^{p} \alpha_{i} \varepsilon_{t-i}^{2}+\sum_{i=1}^{q} \beta_{i} h_{t-j}+\tau d_{t-1}$

The reason of adding the lagged dummy variable in the variance equation, is well described by Doornik and Ooms (2000). The authors show that in a $\operatorname{GARCH}(\mathrm{p}, \mathrm{q})$ model with only a single-observation dummy variable in the mean equation, maximum likelihood estimation can be problematic due to the potential for the bimodality in the likelihood function, while including the lagged dummy variable in the variance equation solves the problem. Doornik and Ooms (2000) prove that if the dummy variable enters to both the mean and variance equations without lag, bimodality remains a potential issue. ${ }^{2}$ In this model the dummy variable in the mean equation sets the corresponding residuals to zero when $\gamma$ is estimated by maximum likelihood.

The above described generalized additive outliers (gao) GARCH $(\mathrm{p}, \mathrm{q})$ model nests both the additive level and the additive volatility outliers without the problem of the bimodality of the log-

\footnotetext{
${ }^{2}$ For more information about the mathematical proof of this assertion, please see the original article by Doornik and Ooms (2000).
} 
likelihood. This gives estimates for the added parameters $\hat{\gamma}$ and $\hat{\tau}$, and a new log likelihood $\hat{l}_{\text {gao }}$.

In the third step, we detect the potential outliers in the series. The null hypothesis is that the largest standardized residuals absolute value $\left(\max _{t}\left|\frac{\varepsilon t}{h_{t}}\right|\right)$ is an outlier date if $2\left(\hat{l}_{g a o}-\hat{l}\right)>C_{T}^{\alpha}$; however, the alternative hypothesis is that the date with $\left(\max _{t}\left|\frac{\varepsilon t}{h_{t}}\right|\right)$ is not corresponding to an outlier if $2\left(\hat{l}_{\text {gao }}-\hat{l}\right)<C_{T}^{\alpha}$. Doornik and Ooms (2005) suggest an approximation of the asymptotic distribution of this test as $C_{T} \approx 5.66+1.88 \log T$, where $T$ indicates the sample size, at a significance $\alpha$ of $5 \%$. If the null hypothesis is confirmed and the first largest standardized residuals absolute value $\left(\max _{t}\left|\frac{\varepsilon_{t}}{h_{t}}\right|\right)$ can be identified as an outlier, we correct it by replacing this value with a new one, which is the corrected value, in this study the new value is obtained by forecasting. This procedure is recursive, meaning that after identifying and correcting the first outlier, we re-estimate the GARCH model with the new dataset and we repeat the three above-described steps to identify the second outlier, the third one, and so on. This process will be repeated until the null hypothesis is rejected and no more outlier is identified, thus the procedure should be terminated. Consequently, we have a time series in which all dates containing outlier values are replaced by our forecasted values and we have a new time series that is so-called outlier corrected dataset. We extend this procedure to the $\operatorname{GJR}(\mathrm{p}, \mathrm{q})$ as well as to the $\operatorname{GARCH}(\mathrm{p}, \mathrm{q})$ models.

This approach has some advantages over the existing outlier detection methods. Doornik and Ooms (2005) suggest an appropriate procedure to compute the $p$-values for the test that does not need simulation. It is a likelihood-based test and the related tests are similar to the GARCH parameters. It is a nested test for the additive level and the additive volatility outliers. Finally, the procedure has the advantage of being extendable to the other types of the GARCH models, such as the EGARCH and the GJR, as well as being expandable to the higher orders of these types of models.

\subsection{The effects of oil price shocks on volatility}

In this section, we analyze the asymmetric effects of oil price shocks on the price volatility of metals by including oil price returns to the variance equation of the GJR model. We apply both the original and the outlier corrected data. The new variance equation is given by:

$$
\begin{aligned}
h_{t}=\alpha_{0} & +\sum_{i=1}^{p} \alpha_{i} \varepsilon_{t-i}^{2}+\sum_{i=1}^{q} \beta_{i} h_{t-j}+\sum_{k=1}^{r} \gamma_{k} I_{t-k} \varepsilon_{t-k}^{2}+\varnothing_{1} O P_{t}^{+} \\
& +\varnothing_{2} O P_{t}^{-}
\end{aligned}
$$

where $O P_{t}^{+}$denotes the positive oil price returns and $O P_{t}^{-}$denotes the negative oil price returns. We follow the Mork (1989) method to separate out the positive and negative shocks, as $O P_{t}^{+}=O P_{t}$ if $O P_{t}>0$ otherwise 0 and $O P_{t}^{-}=O P_{t}$ is $O P_{t}<0$ otherwise 0 . To find the asymmetric reaction of metal prices to the oil price shocks, we apply the Wald test. The null hypothesis is $H_{0}: \varnothing_{1}=\varnothing_{2}$ suggesting no asymmetric reaction and the alternative hypothesis is $H_{1}$ : $\varnothing_{1} \neq \varnothing_{2}$ confirming the asymmetric reaction of each metal price to the oil price shocks.

\section{Results}

\subsection{Outliers in metal markets}

Tables $2 \mathrm{a}$ and $2 \mathrm{~b}$ report the date of detected outliers for each metal, using the Doornik and Ooms (2005) approach under the
Table 2a

Date of detected outliers within GARCH models.

\begin{tabular}{lll}
\hline & GARCH-normal & GARCH- $t$ \\
\hline Aluminum & $26 / 10 / 1993,28 / 11 / 1994,21 / 04 / 2004,13 / 10 / 2004,04 /$ & $4 / 01 / 2005$ \\
& $01 / 2005,27 / 04 / 2010,16 / 11 / 2010$ & \\
Copper & $17 / 09 / 1993,17 / 05 / 1996,05 / 06 / 1996,07 / 06 / 1996,14 /$ & $17 / 09 / 1993$ \\
& $06 / 1996,13 / 10 / 2004,04 / 01 / 2005,16 / 08 / 2007,22 / 09 /$ & \\
& 2011 & $n a$ \\
Lead & $24 / 07 / 1998,13 / 10 / 2003,14 / 10 / 2003$ & $n a$ \\
Nickel & $30 / 05 / 2000,13 / 10 / 2004$ & $n a$ \\
Tin & $n a$ & $n a$ \\
Zinc & $06 / 08 / 1993,29 / 07 / 1997,08 / 07 / 1999$ & $15 / 04 / 2013$ \\
Gold & $31 / 03 / 1995,07 / 07 / 1997,21 / 05 / 2001,11 / 09 / 2001,15 /$ & \\
& $04 / 2013$ & $28 / 08 / 2002$ \\
Palladium & $21 / 09 / 1995,28 / 08 / 2002$ & $n a$ \\
Platinum & $n a$ & $15 / 04 / 2013$ \\
Silver & $21 / 09 / 1995,24 / 01 / 1997,10 / 12 / 1997,21 / 04 / 2006,20 /$ & \\
& $03 / 2008,15 / 08 / 2008,18 / 09 / 2008,15 / 04 / 2013,20 / 06 /$ & \\
& 2013 & \\
\hline
\end{tabular}

Note: na denotes no outlier is detected.

Table 2b

Date of detected outliers within GJR models.

\begin{tabular}{lll}
\hline & GJR-normal & GJR- $t$ \\
\hline Aluminum & $26 / 10 / 1993,28 / 11 / 1994,13 / 10 /$ & $4 / 01 / 2005$ \\
& $2004,04 / 01 / 2005,27 / 04 / 2010,16 /$ & \\
Copper & $11 / 2010$ & \\
& $17 / 09 / 1993,17 / 05 / 1996,05 / 06 / 1996,07 / 06 /$ & $17 / 09 / 1993,13 / 10 /$ \\
& $1996,14 / 06 / 1996,13 / 10 / 2004,04 / 01 / 2005,16 /$ & $2004,04 / 01 / 2005$ \\
Lead & $08 / 2007,22 / 09 / 2011$ & \\
& $24 / 07 / 1998,13 / 10 /$ & $n a$ \\
Nickel & $2003,14 / 10 / 2003$ & $n a$ \\
Tin & $30 / 05 / 2000,13 /$ & \\
Zinc & $10 / 2004$ & $n a$ \\
& $n a$ & $06 / 08 / 1993,29 /$ \\
Gold & $06 / 08 / 1993,29 /$ & $07 / 1997$ \\
& $07 / 1997$ & $15 / 04 / 2013$ \\
Palladium & $07 / 07 / 1997,11 / 09 /$ & \\
& $2001,15 / 04 / 2013$ & $28 / 08 /$ \\
Platinum & $2002 /$ & 2002 \\
Silver & $n a$ & $n a$ \\
& $31 / 03 / 1995,21 / 04 / 2006,15 / 08 /$ & $15 / 04 / 2013$ \\
& $2008,18 / 09 / 2008,15 / 04 / 2013,20 /$ & \\
& $06 / 2013$ & \\
\hline
\end{tabular}

Note: $n a$ denotes no outlier is detected.

GARCH and the GJR models, respectively. We detect outliers applying both normal and Student- $t$ distributions.

The results indicate that under the GARCH model with normal distribution, for aluminum, copper, lead, nickel, zinc, gold, palladium and silver, the number of detected outliers are seven, nine, three, two, three, five, two and nine, respectively; however, under the GARCH model with Student- $t$ distribution no outlier could be detected for lead, nickel and zinc, and only one outlier, which is the biggest one, is identified for aluminum, copper, gold, palladium and silver. Under the GJR model with normal distribution, for aluminum, copper, lead, nickel, zinc, gold, palladium and silver, the number of detected outliers are six, nine, three, two, two, three, one and six, respectively; while under the GJR model with Student- $t$ distribution no outlier is identified for lead, nickel and platinum, one outlier is detected for aluminum, gold, palladium and silver, and three and two outliers are detected for copper and zinc, respectively, which are the biggest outliers. Moreover, under the GARCH and the GJR models with normal and Student- $t$ distributions no outlier could be identified for tin and platinum. 
Among the corresponding events that occurred in the same or around the time of identified outliers and can have roles in arising of outliers, we can mention e.g., to the Schengen agreement; a fierce attack by a hedge fund in June 1996 resulting in copper price falling; the 1997 Asian financial crisis; the 11 September 2001 terrorist attack; Cyprus, Czech Republic, Estonia, Hungary, Latvia, Lithuania, Malta, Poland, Slovakia, and Slovenia joined the EU in 2004; the 2005 South Asian tsunami; the 2007 tsunami warnings in the Pacific Ocean; the 2008 global crisis; the September 2008 stock market crash; the 2008 and the 2012 crude oil price shocks; the 2010 Earthquake in China; the 2010 Mexican oil spill; and the start of the Wall Street protests in the United States in 2011.

Next, we apply the GARCH and the GJR volatility models to examine the persistence of volatility (Section 3.2) and the leverage effects (Section 3.3) in metal markets using the "original data" and the "outlier corrected data". We compare the estimation of the models under four different conditions: (1) original data-normal distribution; (2) original data-Student- $t$ distribution; (3) outlier corrected data-normal distribution; and (4) outlier corrected data-Student- $t$ distribution. Then, we investigate the effects of oil returns on the price volatility of metals, allowing for the asymmetric responses to the negative and positive oil price shocks, using the original and the outlier corrected data (Section 3.4).

\subsection{Persistence of volatility}

\subsubsection{Empirical results}

We apply the ARMA(p,q)-GARCH$(2,2)$ model to estimate the persistence of volatility among metals. Selection of the appropriate models is based on the ARCH test and the Akaike Information Criteria (AIC). For each metal the best model is shown in bold representing the lowest value of the AIC. Furthermore, the residual diagnostic tests results are informed to check for the fitting of the chosen volatility models. The results are reported in Tables $3 a-3 c$.

The results indicate that for all metals the non-negativity conditions are observed. The moment conditions state that for aluminum, copper, nickel, platinum and silver the second moment condition is satisfied within every one of the estimated models, but for lead, tin, zinc, gold and palladium the second moment condition is violated for some of the models. However, the logmoment condition is satisfied for every one of the estimated models for all metals. Therefore, there are sufficient evidences in favor of consistency and asymptotic normality of the QMLE for all metals.

We continue the discussion by comparing the GARCH models in terms of their information criteria to conclude which model shows the highest performance in capturing volatility for each metal. First, for all metals, removing outliers improves the performance of the GARCH model using original data with normal distribution, except for tin and platinum, for which no outlier is detected. Thus, for all metals the GARCH model using the outlier corrected data-normal distribution outperforms the GARCH model using the original data-normal distribution.

Second, we go further to compare the ability of two solutions for capturing the fat tails in returns. One is using Student- $t$ distribution; and another is using the outlier corrected data. Accordingly, the results suggest that, for seven metals, the model using original data-Student- $t$ distribution outperforms the model using the outlier corrected data-normal distribution, except for aluminum that the model using the outlier corrected data-normal distribution outperforms the one using the original data-Student- $t$ distribution; and that no outlier is detected for tin and platinum.

Third, in the next step, we develop the performance of the GARCH models using the original data-Student- $t$ distribution by detecting and correcting the remaining outliers. We find that for aluminum, copper, palladium and silver some outliers can still be detected under the GARCH model with Student- $t$ distribution, this means that Student- $t$ distribution is not able to capture some big shocks in returns of the above-mentioned metals. The results show that the new GARCH model using the outlier corrected dataStudent- $t$ distribution increases the performance of the GARCH model using the original data-Student- $t$ distribution.

In the variance equation, the ARCH term $\left(\alpha_{1}+\alpha_{2}\right)$ captures the short-run persistence and the GARCH term $\left(\beta_{1}+\beta_{2}\right)$ captures the contribution of the shocks to the long-run persistence; hence, if $\left(\beta_{1}+\beta_{2}\right)$ is high, the shocks to volatility do not disappear rapidly. Moreover, $\sum_{i=1}^{p} \alpha_{i}+\sum_{i=1}^{q} \beta_{i}$ captures the volatility persistence, if its value is close to one, the volatility is persistence. Accordingly, we

Table 3a

$\operatorname{ARMA}(p, q)-G A R C H(2,2)$ estimation results.

\begin{tabular}{|c|c|c|c|c|c|c|c|}
\hline & \multicolumn{2}{|c|}{ Variance equation } & \multicolumn{2}{|c|}{ Moment conditions } & \multirow{2}{*}{$\begin{array}{l}\text { Information criteria } \\
\text { AIC }\end{array}$} & \multicolumn{2}{|c|}{ Diagnostics tests } \\
\hline & $\alpha 1+\alpha 2$ & $\beta 1+\beta 2$ & S-M & L-M & & $\begin{array}{l}\text { ARCH } \\
\text { F-stat }\end{array}$ & $\begin{array}{l}\text { Serial correlation } \\
\text { Q-stat }\end{array}$ \\
\hline \multicolumn{8}{|l|}{ Aluminum } \\
\hline Original data-normal & 0.096 & 0.883 & 0.980 & -0.032 & -5.879 & 0.12 & 2.86 \\
\hline Outlier corrected data-normal & 0.028 & 0.965 & 0.990 & -0.008 & -5.923 & 0.02 & 2.72 \\
\hline Original data- $t$ & 0.091 & 0.890 & 0.980 & -0.029 & -5.918 & 0.01 & 0.04 \\
\hline $\begin{array}{l}\text { Outlier corrected data- } t \\
\text { Copper }\end{array}$ & 0.093 & 0.887 & 0.980 & -0.030 & -5.924 & 0.05 & 2.54 \\
\hline Original data-normal & 0.096 & 0.881 & 0.98 & -0.030 & -5.511 & 0.16 & 0.79 \\
\hline Outlier corrected data-normal & 0.080 & 0.893 & 0.97 & -0.030 & -5.570 & 0.06 & 0.68 \\
\hline Original data- $t$ & 0.087 & 0.898 & 0.99 & -0.030 & -5.571 & 0.21 & 6.60 \\
\hline $\begin{array}{l}\text { Outlier corrected data- } t \\
\text { Lead }\end{array}$ & 0.085 & 0.900 & 0.99 & -0.020 & -5.579 & 0.98 & 7.09 \\
\hline Original data-normal & 0.020 & 0.977 & 0.997 & 0.000 & -5.179 & 1.30 & 1.05 \\
\hline Outlier corrected data-normal & 0.019 & 0.978 & 0.998 & 0.000 & -5.195 & 0.46 & 1.17 \\
\hline Original data- $t$ & 0.022 & 0.977 & 1.020 & 0.000 & -5.218 & 2.17 & 4.36 \\
\hline Outlier corrected data- $t$ & na & na & na & na & na & na & na \\
\hline
\end{tabular}

Notes:

L-M denotes log moment condition.

AIC denotes Akaike Information Criterion.

$\mathrm{S}-\mathrm{M}$ denotes the second moment condition.

* indicates statistical significance at $10 \%$ level.

*** indicates statistical significance at $5 \%$ level.

**** indicates statistical significance at $1 \%$ level. 
Table 3b

$\operatorname{ARMA}(\mathrm{p}, \mathrm{q})-\mathrm{GARCH}(2,2)$ estimation results (continued).

\begin{tabular}{|c|c|c|c|c|c|c|c|}
\hline & \multicolumn{2}{|c|}{ Variance equation } & \multicolumn{2}{|c|}{ Moment conditions } & \multirow{2}{*}{$\begin{array}{l}\text { Information criteria } \\
\text { AIC }\end{array}$} & \multicolumn{2}{|c|}{ Diagnostics tests } \\
\hline & $\alpha 1+\alpha 2$ & $\beta 1+\beta 2$ & S-M & L-M & & $\begin{array}{l}\text { ARCH } \\
\text { F-stat }\end{array}$ & $\begin{array}{l}\text { Serial correlation } \\
\text { Q-stat }\end{array}$ \\
\hline \multicolumn{8}{|l|}{ Nickel } \\
\hline Original data-normal & 0.015 & 0.980 & 0.996 & -0.005 & -4.866 & 0.00 & 1.48 \\
\hline Outlier corrected data-normal & 0.014 & 0.982 & 0.996 & -0.004 & -4.883 & 0.05 & 0.88 \\
\hline Original data- $t$ & 0.014 & 0.983 & 0.997 & -0.003 & -4.920 & 0.06 & 8.58 \\
\hline $\begin{array}{l}\text { Outlier corrected data- } t \\
\text { Tin }\end{array}$ & na & na & na & na & na & na & $n a$ \\
\hline Original data-normal & 0.006 & 0.993 & 0.999 & -0.000 & -5.639 & 0.03 & 4.99 \\
\hline Outlier corrected data-normal & na & na & na & na & na & na & na \\
\hline Original data- $t$ & 0.013 & 0.987 & 1.000 & 0.000 & -5.776 & 0.00 & 13.94 \\
\hline $\begin{array}{l}\text { Outlier corrected data- } t \\
\text { Zinc }\end{array}$ & na & na & na & na & na & na & na \\
\hline Original data-normal & 0.012 & 0.987 & 0.999 & -0.001 & -5.482 & 0.14 & 3.96 \\
\hline Outlier corrected data-normal & 0.007 & 0.992 & 0.999 & -0.001 & -5.502 & 0.01 & 3.06 \\
\hline Original data- $t$ & 0,008 & 0.991 & 1.000 & -0.001 & -5.533 & 1.94 & 1.47 \\
\hline Outlier corrected data- $t$ & na & na & na & na & na & na & na \\
\hline
\end{tabular}

Notes:

L-M denotes log moment condition.

AIC denotes Akaike Information Criterion.

$\mathrm{S}-\mathrm{M}$ denotes the second moment condition.

* indicates statistical significance at $10 \%$ level.

*** indicates statistical significance at 5\% level.

**** indicates statistical significance at $1 \%$ level.

Table 3c

$\operatorname{ARMA}(p, q)-G A R C H(2,2)$ estimation results (continued).

\begin{tabular}{|c|c|c|c|c|c|c|c|}
\hline & \multicolumn{2}{|c|}{ Variance equation } & \multicolumn{2}{|c|}{ Moment conditions } & \multirow{2}{*}{$\begin{array}{l}\text { Information criteria } \\
\text { AIC }\end{array}$} & \multicolumn{2}{|c|}{ Diagnostics tests } \\
\hline & $\alpha 1+\alpha 2$ & $\beta 1+\beta 2$ & S-M & L-M & & $\begin{array}{l}\text { ARCH } \\
\text { F-stat }\end{array}$ & $\begin{array}{l}\text { Serial correlation } \\
\text { Q-stat }\end{array}$ \\
\hline \multicolumn{8}{|l|}{ Gold } \\
\hline Original data-normal & 0.005 & 0.993 & 1.000 & -0.002 & -6.546 & 0.32 & 3.86 \\
\hline Outlier corrected data-normal & $0, .004$ & 0.995 & 1.000 & -0.001 & -6.611 & 0.59 & 4.70 \\
\hline Original data- $t$ & 0.087 & 0.919 & 1.010 & -0.006 & -6.649 & $6.50^{* *}$ & 10.36 \\
\hline $\begin{array}{l}\text { Outlier corrected data- } t \\
\text { Palladium }\end{array}$ & na & na & na & na & na & na & na \\
\hline Original data-normal & $3.00 \mathrm{E}-04$ & 0.999 & 0.999 & -0.060 & -5.094 & 0.33 & 5.77 \\
\hline Outlier corrected data-normal & $4.00 \mathrm{E}-04$ & 0.999 & 1.000 & -0.050 & -5.128 & 0.05 & 3.84 \\
\hline Original data- $t$ & 0.311 & 0.704 & 1.010 & -0.092 & -5.221 & 0.09 & 12.48 \\
\hline $\begin{array}{l}\text { Outlier corrected data- } t \\
\text { Platinum }\end{array}$ & 0.006 & 0.993 & 1.000 & -0.001 & -5.229 & 0.47 & 17.63 \\
\hline Original data-normal & 0.042 & 0.954 & 0.997 & -0.006 & -5.916 & 0.03 & 2.64 \\
\hline Outlier corrected data-normal & na & na & na & na & na & na & na \\
\hline Original data- $t$ & 0.006 & 0.993 & 0.999 & -0.001 & $-\mathbf{5 . 9 8 7}$ & 2.64 & 2.74 \\
\hline $\begin{array}{l}\text { Outlier corrected data- } t \\
\text { Silver }\end{array}$ & na & na & na & na & na & na & na \\
\hline Original data-normal & 0.079 & 0.918 & 0.998 & -0.012 & -5.233 & $0, .29$ & 5.43 \\
\hline Outlier corrected data-normal & 0.036 & 0.962 & 0.998 & -0.003 & -5.299 & 0.73 & 4.20 \\
\hline Original data- $t$ & 0.023 & 0.975 & 0.999 & -0.025 & -5.320 & 0.03 & 8.68 \\
\hline Outlier corrected data- $t$ & 0.027 & 0.972 & 0.999 & 0.000 & -5.326 & 0.63 & 8.18 \\
\hline
\end{tabular}

Notes:

L-M denotes log moment condition.

AIC denotes Akaike Information Criterion.

$\mathrm{S}-\mathrm{M}$ denotes the second moment condition.

* indicates statistical significance at $10 \%$ level.

*** indicates statistical significance at 5\% level.

**** indicates statistical significance at $1 \%$ level.

find that for all metals, either before or after removing outliers, this value is high. Moreover, for all metals, except palladium, under the GARCH model with normal distribution, when the data are cleaned up from outliers the values of the ARCH term decrease and the values of the GARCH term increase; however, the values of $\sum_{i=1}^{p} \alpha_{i}+\sum_{i=1}^{q} \beta_{i}$ remain unchanged or change insignificantly. These results are in line with Franses and Ghijsels (1999) for stock markets and Charles and Darné (2014a) for crude oil markets.

\subsubsection{Discussion}

The empirical results achieved three main conclusions. The first one is that for all metals the effect of past volatility on the current 


\begin{tabular}{|c|c|c|c|c|c|c|c|c|}
\hline & \multicolumn{2}{|c|}{ Variance equation } & \multicolumn{2}{|c|}{ Moment conditions } & \multirow{2}{*}{$\begin{array}{l}\text { Leverage effect } \\
r \\
\text { Coefficient }\end{array}$} & \multirow{2}{*}{$\begin{array}{l}\text { Information criteria } \\
\text { AIC }\end{array}$} & \multicolumn{2}{|c|}{ Diagnostics tests } \\
\hline & $\alpha 1+\alpha 2+r / 2$ & $\beta 1+\beta 2$ & S-M & L-M & & & $\begin{array}{l}\text { ARCH } \\
F \text {-stat }\end{array}$ & $\begin{array}{l}\text { Serial correlation } \\
\text { Q-stat }\end{array}$ \\
\hline \multicolumn{9}{|l|}{ Aluminum } \\
\hline Original data-normal & 0.098 & 0.882 & 0.980 & -0.032 & $-0.03(-3.48)^{* * * * *}$ & -5.880 & 0.09 & 3.11 \\
\hline Outlier corrected data-normal & 0.030 & 0.963 & 0.994 & -0.008 & $-0.002(-0.57)$ & -5.923 & 0.02 & 2.73 \\
\hline Original data- $t$ & 0.105 & 0.887 & 0.981 & -0.020 & $-0.022(-1.55)$ & -5.918 & 0.00 & 3.11 \\
\hline $\begin{array}{l}\text { Outlier corrected data- } t \\
\text { Copper }\end{array}$ & 0.096 & 0.884 & 0.981 & -0.030 & $-0.018(-1.27)$ & -5.924 & 0.02 & 2.64 \\
\hline Original data-normal & 0.102 & 0.871 & 0.975 & -0.041 & $0.041(4.81)^{* * * * *}$ & -5.513 & 0.05 & 3.58 \\
\hline Outlier corrected data-normal & 0.080 & 0.903 & 0.984 & -0.024 & $0.031(3.61)^{* * * *}$ & -5.571 & 0.01 & 0.64 \\
\hline Original data- $t$ & 0.088 & 0.894 & 0.983 & -0.028 & $0.023(1.77)^{*}$ & -5.571 & 0.09 & 6.68 \\
\hline $\begin{array}{l}\text { Outlier corrected data- } t \\
\text { Lead }\end{array}$ & 0.087 & 0.898 & 0.985 & -0.025 & $0.030(2.34)^{* * *}$ & -5.583 & 0.61 & 6.56 \\
\hline Original data-normal & 0.018 & 0.979 & 0.998 & -0.003 & 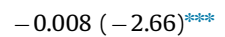 & -5.180 & 1.38 & 0.95 \\
\hline Outlier corrected data-normal & 0.021 & 0.976 & 0.998 & -0.005 & $-0.01(-2.85)^{* * * *}$ & -5.196 & 0.39 & 1.06 \\
\hline Original data- $t$ & 0.021 & 0.977 & 0.999 & -0.003 & $-0.008(-1.52)$ & -5.218 & 2.26 & 4.37 \\
\hline Outlier corrected data- $t$ & na & na & na & na & na & na & na & na \\
\hline
\end{tabular}

Notes:

The values in parentheses are $t$-stats.

L-M denotes log moment condition.

AIC denotes Akaike Information Criterion.

S-M denotes the second moment condition.

**** Denote statistical significance at $1 \%$ level.

* Denote statistical significance at 10\% level.

** Denote statistical significance at 5\% level.

Table $4 b$

$\operatorname{ARMA}(p, q)-G J R(2,2)$ estimation results (continued).

\begin{tabular}{|c|c|c|c|c|c|c|c|c|}
\hline & \multicolumn{2}{|c|}{ Variance equation } & \multicolumn{2}{|c|}{ Moment conditions } & \multirow{2}{*}{$\begin{array}{l}\text { Leverage effect } \\
r \\
\text { Coefficient }\end{array}$} & \multirow{2}{*}{$\begin{array}{l}\text { Information criteria } \\
\text { AIC }\end{array}$} & \multicolumn{2}{|c|}{ Diagnostics tests } \\
\hline & $\alpha 1+\alpha 2+r / 2$ & $\beta 1+\beta 2$ & S-M & L-M & & & $\begin{array}{l}\text { ARCH } \\
F \text {-stat }\end{array}$ & $\begin{array}{l}\text { Serial correlation } \\
\text { Q-stat }\end{array}$ \\
\hline \multicolumn{9}{|l|}{ Nickel } \\
\hline Original data-normal & 0.015 & 0.980 & 0.996 & -0.004 & $-0.003(-1.31)$ & -4.866 & 0.00 & 1.54 \\
\hline Outlier corrected data-normal & 0.014 & 0.981 & 0.996 & -0.004 & $-3 \mathrm{E}-04(-0.13)$ & -4.882 & 0.06 & 1.83 \\
\hline Original data- $t$ & 0.013 & 0.982 & 0.997 & -0.004 & $7 E-04(0.20)$ & -4.918 & 0.09 & 9.27 \\
\hline $\begin{array}{l}\text { Outlier corrected data- } t \\
\text { Tin }\end{array}$ & na & na & na & na & na & na & na & na \\
\hline Original data-normal & 0.007 & 0.992 & 0.999 & -0.001 & $-0.006(-6.41)^{* * * * *}$ & -5.643 & 0.13 & 5.00 \\
\hline Outlier corrected data-normal & na & na & na & na & na & na & na & na \\
\hline Original data- $t$ & 0.012 & 0.988 & 1.00 & -0.000 & $-0.006(-1.96)^{* * *}$ & $-\mathbf{5 . 7 7 7}$ & 0.03 & 13.75 \\
\hline $\begin{array}{l}\text { Outlier corrected data- } t \\
\text { Zinc }\end{array}$ & na & na & na & na & na & $n a$ & na & $n a$ \\
\hline Original data-normal & 0.009 & 0.989 & 0.999 & -0.000 & $-0.007(-3.96)^{* * * * * *}$ & -5.484 & 0.06 & 4.45 \\
\hline Outlier corrected data-normal & 0.010 & 0.988 & 0.999 & -0.000 & $-0.007(-3.61)^{* * * *}$ & -5.491 & 0.10 & 4.11 \\
\hline Original data- $t$ & 0.052 & 0.948 & 1.000 & -0.003 & $-0.02(-2.48)^{* * *}$ & -5.531 & 0.44 & 4.99 \\
\hline Outlier corrected data- $t$ & 0.008 & 0.990 & 0.999 & -0.003 & $-0.004(-2.31)^{* *}$ & -5.537 & 0.60 & 4.75 \\
\hline
\end{tabular}

Notes:

The value L-M denotes log moment condition,s in parentheses are t-stats,

AIC denotes Akaike Information Criterion,

S-M denotes the second moment condition.

* indicates statistical significance at $10 \%$ level.

** indicates statistical significance at 5\% level.

**** indicates statistical significance at $1 \%$ level.

volatility is much greater than the effect of past shocks on the current volatility. This indicates that the past volatility are better factors to use for the prediction of the future volatility among metals rather than the past shocks. The second conclusion is that for all metals either before or after removing outliers, the values of $\sum_{i=1}^{p} \alpha_{i}+\sum_{i=1}^{q} \beta_{i}$ are high, indicating the high degree of persistence in volatility, and that their volatility converge to the long-run equilibrium slowly. ${ }^{3}$ Furthermore, the third conclusion is that after removing outliers from the data, the values of the $\mathrm{ARCH}$ term

\footnotetext{
${ }^{3}$ Among them, gold does not meet the second moment condition under any of the four estimated models and is excluded from this description.
} 
$\operatorname{ARMA}(p, q)-G J R(2,2)$ estimation results (continued).

\begin{tabular}{|c|c|c|c|c|c|c|c|c|}
\hline & \multicolumn{2}{|c|}{ Variance equation } & \multicolumn{2}{|c|}{ Moment conditions } & \multirow{2}{*}{$\begin{array}{l}\text { Leverage effect } \\
r \\
\text { Coefficient }\end{array}$} & \multirow{2}{*}{$\begin{array}{l}\text { Information criteria } \\
\text { AIC }\end{array}$} & \multicolumn{2}{|c|}{ Diagnostics tests } \\
\hline & $\alpha 1+\alpha 2+\gamma / 2$ & $\beta 1+\beta 2$ & S-M & L-M & & & $\begin{array}{l}\text { ARCH } \\
\text { F-stat }\end{array}$ & $\begin{array}{l}\text { Serial correlation } \\
\text { Q-stat }\end{array}$ \\
\hline \multicolumn{9}{|l|}{ Gold } \\
\hline Original data-normal & 0.007 & 0.992 & 1.000 & -0.007 & $-0.002(-3.76)^{* * * * * *}$ & -6.544 & 0.37 & 2.26 \\
\hline Outlier corrected data-normal & 0.018 & 0.982 & 1.000 & -0.020 & $-0.01(-3.01)^{* * \cdots \cdot k}$ & -6.613 & 1.10 & 5.63 \\
\hline Original data- $t$ & 0.044 & 0.958 & 1.000 & -0.001 & $-0.02(-1.03)$ & -6.651 & $6.50^{* * *}$ & 10.06 \\
\hline $\begin{array}{l}\text { Outlier corrected data- } t \\
\text { Palladium }\end{array}$ & 0.048 & 0.954 & 1.000 & -0.001 & $-0.02(-1.17)$ & -6.654 & $3.64^{*}$ & 8.50 \\
\hline Original data-normal & 0.0005 & 0.999 & 0.999 & -0.000 & $3 E-05(0.83)$ & -5.092 & 0.10 & 20.02 \\
\hline Outlier corrected data-normal & 0.001 & 0.998 & 0.999 & -0.000 & $-2 \mathrm{E}-04(-1.11)$ & -5.110 & 0.00 & 24.87 \\
\hline Original data- $t$ & 0.309 & 0.706 & 1.015 & -0.080 & $-5 \mathrm{E}-05(-0.41)$ & -5.218 & 0.07 & 22.68 \\
\hline $\begin{array}{l}\text { Outlier corrected data- } t \\
\text { Platinum }\end{array}$ & 0.298 & 0.716 & 1.010 & -0.080 & $-0.002(-0.15)$ & -5.226 & 0.02 & 18.75 \\
\hline Original data-normal & 0.069 & 0.944 & 0.997 & -0.007 & $-0.03(-4.40)^{* k * * k}$ & -5.921 & 0.02 & 2.85 \\
\hline Outlier corrected data-normal & na & na & na & na & na & na & na & na \\
\hline Original data- $t$ & 0.015 & 0.988 & 0.999 & -0.080 & $-0.09(-2.53)^{* * *}$ & -5.9907 & 1.50 & 2.95 \\
\hline $\begin{array}{l}\text { Outlier corrected data- } t \\
\text { Silver }\end{array}$ & $n a$ & na & na & na & na & na & na & na \\
\hline Original data-normal & 0.087 & 0.929 & 0.998 & -0.009 & 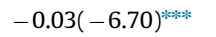 & -5.236 & 0.06 & 6.38 \\
\hline Outlier corrected data-normal & 0.046 & 0.967 & 0.998 & -0.002 & $-0.03(-5.97)^{* * * * *}$ & -5.295 & 0.62 & 4.93 \\
\hline Original data- $t$ & 0.047 & 0.970 & 0.999 & -0.002 & $-0.03(-3.35)^{* * * * *}$ & -5.329 & 0.00 & 9.25 \\
\hline Outlier corrected data- $t$ & 0.047 & 0.969 & 0.999 & -0.003 & $-0.03(-3.27)^{* * * *}$ & -5.333 & 0.35 & 9.38 \\
\hline
\end{tabular}

Notes:

The values in parentheses are t-stats.

L-M denotes log moment condition.

AIC denotes Akaike Information Criterion.

S-M denotes the second moment condition.

* indicates statistical significance at $10 \%$ level.

** indicates statistical significance at 5\% level.

*** indicates statistical significance at $1 \%$ level.

decrease and the value of the GARCH term increase, Carnero et al. (2001, 2007) explain these biases as a result of some big isolated outliers. This means that one isolated outlier at time $t$ affects the estimation of the conditional variance at time $t+1$, then this variance will be used in the estimation of the conditional variance at time $t+2$ and so on. Consequently, an isolated outlier behaves as a patch of outliers for the estimation of the conditional variances and the GARCH parameters. This explains the different behavior of the QMLE estimator for the GARCH model with and without outliers. Within the time span of this study, the 11 September 2001 terrorist attack, the 2010 China Earthquake, and the 2005 South Asian tsunami are some examples for big isolated outliers that can affect metal markets. Moreover, the biases in the GARCH parameters can be a result of some sequential outliers. This suggests that the area of outliers due to the uncertainty associated with an extreme event period such as wars have a successive effect on the parameters of the GARCH model (Carnero et al., 2001, 2007; Charles and Darné, 2014b). Although no war occurred during the time span of this study, we can still indicate the 1997 Asian and the 2008 world financial crisis and the 2008 and the 2012 crude oil price shocks as examples of sequential outliers in metal markets that affect the parameters estimations of the GARCH models.

\subsection{Leverage effects}

\subsubsection{Empirical results}

We apply the ARMA(p,q)-GJR(2,2) model to estimate the existence of leverage effect among metal markets. The selection of appropriate models is based on the ARCH test and the Akaike Information Criteria (AIC). For each metal the best model is shown in bold, representing the lowest value of the AIC. Furthermore, the residual diagnostic tests results are informed to check for the fitting of the chosen volatility models. The results are reported in Tables 4a-4c.

We start with the assumptions that in a GJR model, if the $\gamma>0$ there is a leverage effect. The leverage effect refers to the relationship between returns and volatility, indicating that volatility increases when the returns fall (bad news) as debt-to-equity ratio increases; and volatility decreases when the returns increase (good news). Moreover, $\alpha$ indicates the effective coefficient linked to the positive shocks (good news) and $\alpha+\gamma$ represents the effective coefficient related to the negative shocks (bad news) and if $\alpha+\gamma>\alpha$ then there is an asymmetric effect. The asymmetry phenomenon declares that bad news increase volatility more than good news decrease it. In this section, the aim is to show if there is a leverage effect in metal markets while taking outliers into account.

The results in Tables $4 a-4 c$ reveal that for all metals the nonnegativity condition is observed. The second moment condition is satisfied for aluminum, copper, lead, nickel, platinum and silver under all estimated models, but it is violated for some estimated models of tin, zinc, gold and palladium. Nevertheless, the logmoment condition is satisfied for all metals. Consequently, there are sufficient evidences in favor of consistency and asymptotic normality of the QMLE for all metals under the ARMA(p,q)-GJR $(2,2)$ model.

In order to evaluate the existence of the leverage affect in metal markets, we compare the results under the four estimated models. First, under the GJR model using the original data-normal distribution, for eight metals the $\gamma$ term is statistically significant. However, for seven of them the $\gamma$ term is negative, including aluminum, lead, tin, zinc, gold, platinum and silver, indicating the existence of an inverse leverage effect. Conversely, for copper the $\gamma$ term is positive suggesting the existence of a leverage effect. Moreover, for nickel and palladium the $\gamma$ term is not statistically significant under this model. These findings are in line with 
Hammoudeh and Yuan (2008) who suggest the leverage effect only for the copper market and the inverse leverage effect for the gold and silver markets, and in line with Chkili et al. (2014) who find an inverse leverage effect for the gold and silver markets. Accordingly the authors suggest that gold and silver can be good investments in prospect of bad news, In another study Carpantier (2010) finds the leverage effect for the stock markets and the inverse leverage effect for commodity markets, including metals and agricultures. Moreover, Engle (2011) provides evidences in favor of a negative sign of the $\gamma$ term for gold, some exchange rates, some interest rates and some volatility index return series and interprets this as a hedge effect. Nonetheless, our results are in contrast with Gil-Alana and Tripathy (2014) who find the leverage effect in Indian non-precious metal markets, including aluminum, copper, lead, tin and zinc. The only exception is nickel, for which neither our study nor the study by Gil-Alana and Tripathy (2014) find any asymmetric behavior. These contradictory results lead us to the different behaviors of international exchange markets, meaning that the LME as a developed market, and the Indian commodity exchange market, as a less developed market, are not alike. Perhaps the Indian commodity exchange market still suffers from some imperfections such as governmental controlling and domestic traders with lack of sufficient trading experiences.

Second, under the GJR model using the outlier corrected datanormal distribution, for five metals, including copper, lead, zinc, gold and silver, the $\gamma$ term still is statistically significant but for aluminum, detected outliers have been the sources of the leverage effect, as cleaning the data from outliers removes the asymmetry evidence. However, for tin and platinum no outlier is detected; therefore, the GJR model is not estimated for them. Finally, for palladium and nickel the results are the same as the first model and no leverage effect is detected for them.

Third, under the GJR model using the original data-Student- $t$ distribution, the results suggest that for five metals, including copper, tin, zinc, platinum and silver, the $\gamma$ term is still statistically significant, and for lead, nickel and gold, it is no longer statistically significant. This indicates that Student- $t$ distribution is capturing the outliers that were leading to an asymmetric effect in these three metals.

Fourth, under the GJR model using the outlier corrected dataStudent- $t$ distribution, the $\gamma$ term is statistically significant only for copper, zinc and silver. This means that, correcting the data from outliers, as well as using Student- $t$ distribution remove the sources of asymmetry in the rest of metals.

\subsubsection{Discussion}

The results suggest the existence of inverse leverage effect for seven metals, including aluminum, lead, tin, zinc, gold, platinum and silver. As the existence of a leverage effect in stock markets is well known in the literature, evidences in favor of an inverse leverage effect is supported for commodity markets. This reflects that in commodity markets, volatility tends to be high when returns increase; in this case, supplies or inventory levels of commodities tend to be scarce. For instance, Carpantier (2010) explains that an increase in price potentially represents the decline of the commodities inventories, consequently the author suggests that this phenomenon can be called "inventory effect". Moreover, the results suggest the existence of leverage effect and asymmetry in favor of bad news in the copper market, which emphasizes developing financialization and departing from the characteristics of a commodity market for copper.

When comparing the results from the GJR and the GARCH models to capture the pattern of volatility, according to the Akaike Information Criteria, there are strong evidences in favor of priority of the GJR model over the GARCH model. This means that the price volatility of metals can be better explained by a model that contains the asymmetry features.

To check the validity of normal distribution, the results show that for all metals there are evidences for the existence of skewness and excess kurtosis, the Jarque-Bera tests are significant as well. These results confirm the findings of Bollerslev (1987) and Teräsvirta (1996) who show that the GARCH models cannot fully capture excess kurtosis in high frequency financial data. However, after cleaning up the data from outliers, skewness, excess kurtosis and Jarque-Bera are substantially reduced, but still they are statistically significant. ${ }^{4}$ This indicates that outliers can lead to excess kurtosis in the data (see Balke and Fomby, 1994; Fiorentini and Maravall, 1996; Charles and Darné, 2005, 2014a,b).

\subsection{The effects of oil price shocks on volatility of metal markets}

\subsubsection{Empirical results}

The results of the volatility estimations in previous section suggest that the GJR model outperforms the GARCH model to capture the pattern of volatility in metal markets. Hence, we use the ARMA-GJR(2,2) model with normal distribution, using both the original and the outlier corrected data to estimate the effects of oil price shocks on the price volatility of metals. We allow for the asymmetric responses to the oil price changes by splitting up the oil price increases and decreases as the separate variables. ${ }^{5}$ The results are reported in Table 5.

We start by analyzing the effects of oil price shocks on the volatility of metals, using the original data. For aluminum, the sign of negative oil price shocks on volatility is negative, representing that they increase volatility. However, the positive oil price shocks do not impact on the volatility of aluminum. For copper, nickel and palladium, the sign of negative oil price shocks is negative and the sign of positive shocks is positive meaning that either the negative or the positive oil price shocks increase their volatility. For lead, tin and platinum, the sign of negative and positive shocks on volatility is negative indicating that the negative oil price shocks increase volatility and the positive oil price shocks decrease it. For zinc and gold, the sign of negative oil price shocks on volatility is positive, specifying that the negative oil price shocks decrease volatility; however, the positive oil price shocks do not affect their volatility. Finally the negative shocks do not affect the volatility of silver, while the sign of positive oil price shocks on volatility is negative, meaning that these shocks decrease the price volatility of silver. However, even for metals with statistically significant oil shocks effect, the values of coefficients are insignificant, indicating a very small and negligible effect of oil price shocks on those volatilities.

Then, we go further to understand the existence of asymmetric reaction from metal prices volatility to oil price shocks. We use the Wald test with the null hypothesis of $H_{0}: \varnothing_{1}=\varnothing_{2}$ suggesting no asymmetric reaction and the alternative hypothesis of $H_{1}: \varnothing_{1} \neq \varnothing_{2}$ conforming the asymmetric reaction. The results show that there are evidences of an asymmetric effect in favor of the positive shocks for lead, tin and silver, and in favor of the negative shocks for aluminum, zinc, gold and palladium. Moreover, no asymmetric reaction is identified for copper, nickel and platinum, The results are reported in Table 5.

Next, we analyze the effects of oil price shocks on volatility, using outlier corrected data. The results reveal that for lead, zinc, gold and palladium the estimation using the outlier corrected data is equal to those using the original data, and for tin and platinum no outlier could be detected from the previous section. However, for aluminum and nickel the effects of oil price shocks are not

\footnotetext{
${ }^{4}$ These results are available upon request from the authors.

${ }^{5}$ For robustness check we perform the same analysis using the GARCH model as well, which confirms the results of the GJR model for the majority of metals, the results are available upon request from the authors.
} 
Table 5

The effects of oil price shocks on volatility of metal markets.

\begin{tabular}{|c|c|c|c|c|c|}
\hline & \multicolumn{2}{|c|}{ ARMA-GJR(2,2)-original data } & \multirow{2}{*}{$\begin{array}{l}\text { Asymmetric effects } \\
\text { Wald test- } F \text { stat }\end{array}$} & \multicolumn{2}{|c|}{ ARMA-GJR(2,2)-outlier corrected data } \\
\hline & $O P_{t}^{+}$ & $O P_{t}^{-}$ & & $O P_{t}^{+}$ & $O P_{t}^{-}$ \\
\hline Aluminum & $\begin{array}{l}-6, \mathrm{E}-{ }^{*} 06 \\
(-0.08)\end{array}$ & $\begin{array}{l}-1, \mathrm{E}-04 \\
(-3.49)^{*}\end{array}$ & $5.47 * *$ & $\begin{array}{l}1, E-04 \\
1.44\end{array}$ & $\begin{array}{l}-1, \mathrm{E}-05 \\
-0.17\end{array}$ \\
\hline Copper & $\begin{array}{l}2, \mathrm{E}-04 \\
(2.19)^{* * *}\end{array}$ & $\begin{array}{l}-3, E-04 \\
(-3.91)^{*}\end{array}$ & 0.07 & $\begin{array}{l}1, \mathrm{E}-04 \\
(1.73)^{*}\end{array}$ & $\begin{array}{l}-8, E-05 \\
(-0.96)\end{array}$ \\
\hline Lead & $\begin{array}{l}-1, \mathrm{E}-04 \\
(-3.68)^{* * * * k}\end{array}$ & $\begin{array}{l}-5, \mathrm{E}-05 \\
(-1.68)^{*}\end{array}$ & $4.18^{* * *}$ & $\begin{array}{l}-1, E-04 \\
(-3.61)^{* * *}\end{array}$ & $\begin{array}{l}-1, \mathrm{E}-04 \\
(1.87)^{*}\end{array}$ \\
\hline Nickel & $\begin{array}{l}4, E-04 \\
(2.44)^{* * *}\end{array}$ & $\begin{array}{l}-5, \mathrm{E}-04 \\
(-3.36)^{* * * k \cdots}\end{array}$ & 0.17 & $\begin{array}{l}2, E-05 \\
(0.39)\end{array}$ & $\begin{array}{l}-4, E-05 \\
(-0.83)\end{array}$ \\
\hline Tin & $\begin{array}{l}-2, \mathrm{E}-05 \\
(-2.52)\end{array}$ & $\begin{array}{l}1, \mathrm{E}-05 \\
(1.71)^{*}\end{array}$ & $28.24^{* * * *}$ & $\begin{array}{l}-2, \mathrm{E}-05 \\
(-2.52)\end{array}$ & $\begin{array}{l}1, E-05 \\
(1.71)^{*}\end{array}$ \\
\hline Zinc & $\begin{array}{l}-6, \mathrm{E}-05 \\
(-1.22)\end{array}$ & $\begin{array}{l}1, \mathrm{E}-04 \\
(2.73)^{* * * k * *}\end{array}$ & $740.46^{* * * * *}$ & $\begin{array}{l}4, E-06 \\
(-0.33)\end{array}$ & $\begin{array}{l}1, \mathrm{E}-05 \\
(1.80)^{* * * * *}\end{array}$ \\
\hline Gold & $\begin{array}{l}6, E-06 \\
(0.75)\end{array}$ & $\begin{array}{l}1, \mathrm{E}-05 \\
(1.83)^{*}\end{array}$ & $135.92^{* * \cdots * k}$ & $\begin{array}{l}4, E-06 \\
(1.00)\end{array}$ & $\begin{array}{l}1, \mathrm{E}-05 \\
(2.57)^{* * *}\end{array}$ \\
\hline Palladium & $\begin{array}{l}4, \mathrm{E}-04 \\
(2.99)^{* * * * *}\end{array}$ & $\begin{array}{l}-0.002 \\
(8.61)^{* * * * *}\end{array}$ & $61.73^{* * * *}$ & $\begin{array}{l}8, \mathrm{E}-04 \\
5.60^{* * * * *}\end{array}$ & $\begin{array}{l}-0.001 \\
-7.29^{\text {*k*** }}\end{array}$ \\
\hline Platinum & $\begin{array}{l}-1, \mathrm{E}-04 \\
(-4.70)^{* * * *}\end{array}$ & $\begin{array}{l}-1, \mathrm{E}-04 \\
(3.78)^{* * * * *}\end{array}$ & 2.77 & $\begin{array}{l}-1, \mathrm{E}-04 \\
(-4.70)^{* * * *}\end{array}$ & $\begin{array}{l}-1, \mathrm{E}-04 \\
(3.78)^{* * * k *}\end{array}$ \\
\hline Silver & $\begin{array}{l}-8, \mathrm{E}-05 \\
(-8.59)^{* * * *}\end{array}$ & $\begin{array}{l}1, E-09 \\
(0.0005)\end{array}$ & $101.61^{* * * *}$ & $\begin{array}{l}-1, E-04 \\
(-3.37)^{* * * *}\end{array}$ & $\begin{array}{l}2, E-06 \\
(0.084)\end{array}$ \\
\hline
\end{tabular}

Notes: The values in parentheses are $t$-stats.

* Denote statistical significance at $10 \%$.

** Denote statistical significance at 5\% level.

*** Denote statistical significance at $1 \%$ level.

statistically significant after removing outliers from the data; besides, for copper and silver only the effect of positive shocks remains significant after correcting the data from outliers. The results are reported in Table 5.

\subsubsection{Discussion}

One main conclusion is that the negative oil price shocks increase volatility of seven metals, except gold, silver and zinc, and second, the positive oil price shocks decrease the volatility of lead, tin, platinum and silver, and increase the volatility of copper, nickel and palladium. This transmission can occur through two main channels. The first one is that the negative oil price shocks or bad news in the oil market push the traders away from oil toward other commodities, i.e. metals and agricultures. The second channel is that the negative oil price shocks are actually good news for the economy, it stimulates economic activities and industrial production in oil importing countries. This again boosts demand for metals with industrial application. Consequently, the negative oil price shocks increase the financial and the physical demands for metals with industrial application. This decreases their inventory levels and following the existence of inverse leverage effect in these markets, their price volatility increases.

Nevertheless, gold and silver as the main precious metals are excluded from the above described transaction channels. Gold has less industrial application and it is mainly applied in jewelry industries. There is a general consensus that the prices of gold and oil are positively correlated, the main idea behind it is due to the inflationary effect of oil prices. Moreover, oil is a significant direct and indirect cost input to the gold production process; hence, the lower oil price helps the bottom lines of gold mining companies. These prove that the negative oil price shocks reduce the gold price, which is good news for the gold market as a commodity. Therefore, this good news calms the gold market and reduces the volatility of the gold price. However, silver as a precious metal has more industrial applications than gold, in fact this metal is used in both the jewelry and industrial sectors. This can be the reason why the negative oil price shocks has less effect on the price volatility of silver; the shocks have a negative effect as they have on gold but it is statistically insignificant.

On another side, the results show that explaining the effects of positive oil price shocks on metal markets is more complicated than explaining the negative ones. The positive oil price shocks do not affect the volatility of aluminum, gold and zinc. However, they decrease the volatility of lead, tin, platinum and silver. The first channel of this transmission is that good news in the oil market push the traders away from other commodity markets to oil. Moreover, the positive oil price shocks can be interpreted as a depreciation of the world economy. This leads to a reduction of industrial production and a lower consumption of industrial metals. Finally their prices may decrease and according to the inverse leverage effect that exists in these markets, their volatility decrease as well.

In the case of copper, nickel and palladium, the results are different from those of other metals, as both the negative or the positive oil price shocks increase their volatility. The interesting point is that the results from the previous section indicated that seven metals showed an inverse leverage effect; however, these three metals were excluded from this effect, as copper showed a leverage effect, while for nickel and palladium the asymmetry term was not statistically significant. One can conclude that the properties of the leverage effect as well as the effect of oil price shocks on these markets change over time.

Furthermore, after correcting the data from outliers, we find that for aluminum and nickel the oil price shocks no longer affect their volatility, while only the positive shocks remain significant for copper and silver. This means that some of the effects of oil price shocks on the volatility of these metals are removed after cleaning up the data from outliers. The reason is that some detected outliers in metal markets can be due to the shocks in the oil market, another reason is that volatility in both markets could be effected by the same events, some examples of these events are the 1997 Asian and the 2008 world financial crisis; the 2008 and the 2012 oil price shocks; the 2010 Mexican oil spill, etc. 


\section{Conclusion}

The price volatility of metals is an interesting subject for financial traders and manufacturers. Volatility affects the decision of investors for portfolio allocation and Value at Risk management strategies, as well as the industrial production of manufacturers and therefore the economic growth pattern of nations. As a result, the correct modeling of volatility in these markets is a crucial issue, which on one side increases the ability to generate an accurate out-of-sample forecasting for policymakers, and on another side facilitates the Value at Risk management strategies for financial traders.

In this study we have two main objectives: (i) the first one is to examine the persistence of volatility and the leverage effect, taking into account the exogenous shocks and sudden events as outliers in the data. To achieve this goal we use two alternative approaches to capture outliers. The first one is Student- $t$ distribution; and the second one is identifying and correcting outliers in the GARCH and the GJR models applying the Doornik and Ooms (2005) procedure. Furthermore, (ii) the second one is to examine the effect of oil price shocks on the price volatility in metal markets, using the GJR model while allowing for the asymmetric responses to the oil returns changes.

The main findings are that: first, for all metals, outliers bias the estimation of parameters of the GARCH model and second, removing outliers improves the performance of the models. Third, except for aluminum, the model using the original data-Student- $t$ distribution outperforms the model using the outlier corrected data-normal distribution. Fourth, either before or after correcting outliers returns show a high degree of persistence in volatility. Fifth, there is evidence of the inverse leverage effect in seven metals, including aluminum, lead, tin, zinc, gold, platinum and silver and the leverage effect for copper. Finally sixth, metal markets react to oil price shocks in different ways and there are evidences in favor of the asymmetric reaction of volatility to oil price shocks only in seven metals.

Our findings are important for all beneficiaries of investigations in metal markets, including policymakers, financial traders and manufacturers. In particular, our results suggest that Value at Risk estimation and risk management plans can be made more accurate if the quality of out-of-sample forecasting in metal markets is improved. This means that the effects of exogenous events, as well the asymmetric effects of oil price shocks, should be considered while modelling metal markets volatility.

\section{Acknowledgments}

The authors acknowledge financial support from the "Energy: Resources and Markets" research program of Fondazione Eni Enrico Mattei (FEEM). Moreover, we thank anonymous reviewer (s) and editor of the journal for their helpful contributions that enhanced the quality of the paper.

\section{References}

Aggarwal, R., Inclan, C., Leal, R., 1999. Volatility in emerging markets. J. Financ. Quant. Anal. 34, 33-55.

Ané, T., Loredana, U.R., Gambet, J.B., Bouverot, J., 2008. Robust outlier detection for Asia-Pacific stock index returns. J. Int. Financ. Markets Inst. Money 18, 326-343.

Balke, N.S., Fomby, T.B., 1994. Large shocks, small shocks, and economic fluctuations: outliers in macroeconomic time series. J. Appl. Econ. 9, 181-200.

Bollerslev, T., 1987. A conditional heteroskedastic time series model for speculative prices and rates of return. Rev. Econ. Stat. 69, 542-547.

Carnero, M.A., Peña, D., Ruiz, E., 2001. Outliers and conditional autoregressive heteroskedasticity in time series. Rev. Estad. 53, 143-213.
Carnero, M.A., Peña, D., Ruiz, E., 2007. Effects of outliers on the identification and estimation of GARCH models. J. Time Ser. Anal. 28, 471-497.

Carnero, M.A., Peña, D., Ruiz, E., 2012. Estimating GARCH volatility in the presence of outliers. Econ. Lett. 114, 86-90.

Carpantier, J.F., 2010. Commodities inventory effect. Center for Operations Research and Econometrics. Core discussion paper.

Chang, I., Tiao, G.C., Chen, C., 1988. Estimation of time series parameters in the presence of outliers. Technometrics 30, 193-204.

Charles, A., Darné, O., 2005. Outliers and GARCH models in financial data. Econ. Lett. 86, 347-352.

Charles, A., 2008. Forecasting volatility with outliers in GARCH models. J. Forecast. 27, $551-565$.

Charles, A., Darné, O., 2014a. Volatility persistence in crude oil markets. Energy Policy 65, 729-742.

Charles, A., Darné, O., 2014b. Large shocks in the volatility of the Dow Jones Industrial Average index: 1928-2013. J. Bank. Financ. 43, 188-199.

Charlot, P., Marimoutou, V., 2014. On the relationship between the prices of oil and the precious metals: revisiting with a multivariate regime-decision tree. Energy Econ. 44, 456-467.

Chen, C., Liu, L.M., 1993. Joint estimation of model parameters and outlier effects in time series. J. Am. Stat. Assoc. 88, 284-297.

Chkili, W., Hammoudeh, S., Nguyen, D.K., 2014. Volatility forecasting and risk management for commodity markets in the presence of asymmetry and long memory. Energy Econ. 41, 1-18.

Choi, K., Hammoudeh., S., 2010. Volatility behavior of oil, industrial commodity and stock markets in a regimeswitching environment. Energy Policy 38, 4388-4399.

Dickey, D.A., Fuller, W.A., 1979. Distribution of the estimators for autoregressive time series with a unit root. J. Am. Stat. Soc. 75, 427-431.

Dijk, D.V., Franses, P.H., Lucas, A., 1999. Testing for ARCH in the presence of additive outliers. J. Appl. Econ. 14, 539-562.

Doornik, J.A., Ooms, M., 2000. Multimodality in the GARCH Regression Model. Nuffield College, Mimeo.

Doornik, J.A., Ooms, M., 2005. Outlier Detection in GARCH Models. Discussion Paper No 2005-092/4, Tinbergen Institute.

Engle, R.F., 2011. Long-Term Skewness and Systemic Risk. Journal of Financial Econometrics 9, 437-468.

Ewing, B.T., Malik, F., 2013. Volatility transmission between gold and oil futures under structural breaks. In. Rev. Econ. Financ. 25, 113-121.

Fiorentini, G., Maravall, A., 1996. Unobserved components in ARCH models: an application to seasonal adjustment. J. Forecast. 15, 175-201.

Franses, P.H., Ghijsels, H., 1999. Additive outliers, GARCH and forecasting volatility. J. Forecast. 15, 1-9.

Gil-Alana, L.A., Tripathy, T., 2014. Modelling volatility persistence and asymmetry: a Study on selected Indian nonferrous metal markets. Resour. Policy 41, 31-39.

Glosten, L.R., Jaganathan, R., Runkle, D., 1993. On the relation between the expected value and the volatility of the normal excess return on stocks. J. Financ. 48, 1779-1801.

Hammoudeh, S., Yuan, Y., 2008. Metal volatility in presence of oil and interest rate shocks. Energy Econ. 30, 606-620.

Hammoudeh, S., Malik, F., McAlee, M., 2011. Risk management of precious metals. Q. Rev. Econ. Fin 51, 435-441.

Hotta, L.K., Tsay, R.S., 1998. Outliers in GARCH processes. Manuscript. University of Chicago.

Jain, A., Ghosh, A., 2013. Dynamics of global oil prices, exchange rate and precious metal prices in India. Resour. Policy 38, 88-93.

Ji, Q., Fan, Y., 2012. How does oil price volatility affect non-energy commodity markets? Appl. Energy 89, 273-280.

Laurent, S., Lecourt, C., Palm, F.C., 2013. Testing for Jumps in GARCH Models, A Robust Approach. Working paper.

Ling, S., McAleer, M., 2002a. Necessary and sufficient moment conditions for the $\operatorname{GARCH}(\mathrm{r}, \mathrm{s})$ and asymmetric power GARCH(r,s) models. Econ. Theory 18 , 722-729.

Ling, S., McAleer, M., 2002b. Stationarity and the existence of moments of a family of GARCH processes. J. Econ. 106, 109-117.

Liu, M.L., Ji, Q., Fan, Y., 2013. How does oil market uncertainty interact with other markets? An empirical analysis of implied volatility index. Energy 55, 860-868.

Mackenzie, M., Mitchell, H., Brooks, R., Faff, R., 2001. Power ARCH modeling of commodity futures data on the London's Metal Market. Eur. J. Financ. 7, 22-38.

McAleer, M., Chan, F., Marinova, D., 2002. An Econometric Analysis of Asymmetric Volatility: Theory and Application to Patents. Presented to the Australasian Meeting of the Econometric Society, Brisbane.

Mendes, B.V.M., 2000. Assessing the bias of maximum likelihood estimates of contaminated GARCH models. J. Stat. Commun. Simul. 67, 359-376.

Mensi, W., Beljid, M., Boubaker, A., Managi, S., 2013. Correlations and volatility spillovers across commodity and stock markets: Linking energies, food, and gold. Econ. Model. 32, 15-22.

Moore, M.J., Cullen, U., 1995. Speculative efficiency on the London Metal Exchange. Manch. Sch. 63, 235-256.

Morales, Lucía, O'Callaghan, B.A., 2011. Comparative analysis on the effects of the Asian and global financial crises on precious metal markets. Res. Int. Bus. Financ. 25, 203-227.

Mork, K.A., 1989. Oil and the macroeconomy when prices go up and down: an extension of Hamilton's results. J. Polit. Econ. 97, 740-744.

Nelson, D.B., 1990. Stationarity and persistence in the GARCH(1,1) model. J. Econ. 45, 7-38. 
Phillips, P.C.B., Perron, P., 1988. Testing for a unit root in time series regressions. Biometrica 75, 335-346.

Sakata, S., White, H., 1998. High breakdown point conditional dispersion estimation with application to S\&P 500 daily returns volatility. Econometrica 66, 529-567.

Sari, R., Hammoudeh, S., Soytas, U., 2010. Dynamics of oil price, precious metal prices and exchange rate. Energy Econ. 32, 351-362.

Soytas, U., Sari, R., Hammoudeh, S., Hacihasanoglu, E., 2009. World oil prices, precious metal prices and macroeconomy in Turkey. Energy Policy 37, 5557-5566.
Teräsvirta, T., 1996. Two stylized facts and t he GARCH(1,1) model. Working Paper No 96, Stockholm School of Economics.

Todorova, N., Worthington, N., Souček, M., 2014. Realized volatility spillovers in the non-ferrous metal futures market. Resour. Policy 39, 21-31.

Tsay, R.S., 1986. Time series models specification in the presence of outliers. J. Am. Stat. Assoc. 81, 132-141.

Zhang, X., King, M., 2005. Influence ingeneralized autoregressive conditional heteroscedasticity processes. J. Bus. Econ. Stat. 23, 118-129.

Zhang, Y.J., Wei, Y.M., 2010. The crude oil market and the gold market: evidence for cointegration, causality and price discovery. Resour. Policy 35, 168-177. 